J. Perinat. Med. 16 (1988) 365

\title{
Computerized assessment of fetal behavioral states
}

\author{
Frank J. M. Caron, Herman P. van Geijn, Emilie E. van Woerden, J. Marco Swartjes, \\ and Robert Mantel
}

Department of Obstetrics and Gynecology, Academic Hospital, Free University, Amsterdam, The Netherlands

\section{Introduction}

Fetal heart rate and fetal movements are parameters providing information on the fetal condition. They are non-invasive and relatively easy to attain. Recently we applied the method of maternal perception to study fetal movements [7]. The current study uses real-time ultrasound to observe fetal movements directly.

In the near term human fetus, four behavioral states have been described on the basis of the heart rate pattern, eye movements and body movements $[5,6,10]$. These states are: $1 \mathrm{~F}$ (quiet sleep), $2 \mathrm{~F}$ (active sleep), 3F (quiet awake) and 4F (active awake).

The study our research group is performing aims to examine fetal heart rate, fetal movements, and fetal behavioral states in physiological pregnancies $[12,13]$, pregnancies with maternal antiepileptic medication $[8,11]$ and pregnancies complicated by severe intrauterine growth retardation.

In order to improve the accessability of the fetal behavioral state concept, we needed a recording system, which is easy to handle, and excludes as many potential error sources as possible. The availability of a minicomputer system in the department of obstetrics and gynecology facilitated the development of a computerized system for acquisition and storage of fetal heart rate signals and fetal movement markers. Computer assisted recognition of fetal behavioral states, calculation of fetal heart rate indices and analysis of fetal movements have been programmed. This article describes the techniques we apply in our studies.

\section{Curriculum vitae}

Frank Caron, M.Sc., was born in 1953. From 1972 to 1979 he studied electrotechnical engineering at the Technical University of Delft, The Netherlands. During his studies, he specialized in computing. Since 1980 he has been working at the Department of Obstetrics and Gynecology at the Acade-

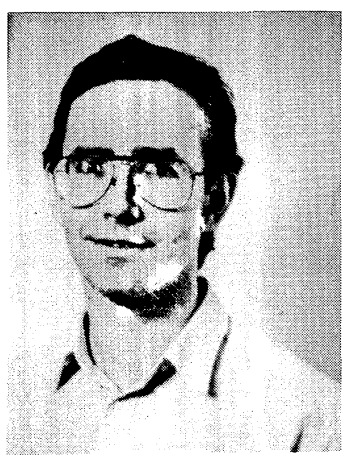
mic Hospital of the Free University in Amsterdam, where he developed software for research purposes.

\section{Instrumentation, storage and display}

\subsection{Instrumentation}

The fetal electrocardiogram is obtained from the maternal abdominal wall. For this purpose a Hewlett Packard cardiotocograph HP8030 is used. HP8030 monitor generates flash pulses, corresponding to the R-speaks in the fetal ECG. These pulses are sent to a home-made interface connected to the computer. As to the determination of the statistical heart rate parameters, which are discussed later on, the fetal ECG is prefered for its beat-to-beat properties. However, it appears not always possible to attain a fetal ECG of sufficient quality. In order to be informed about the heart rate patterns required for the determination 
of fetal behavioral states under any circumstance, a wide-range Doppler ultrasound unit HP8040 is used in case of bad quality fetal ECG. The HP8040 monitor supplies an analog signal which fluctuates with the fetal heart rate. This analog signal is sampled and $\mathrm{AD}$-converted at a rate of 10 times per second. These samples are subsequently stored on disk.

Two real-time ultrasound units (Toshiba SAL 20A, and Squibb Mark 100, both with a $3.5 \mathrm{MHz}$ linear array transducer of $8 \mathrm{~cm}$ ) are used to observe fetal movements. One transducer is directed to the fetal head to observe eye movements, mouth movements, grimace, yawn, and rotation and retroflexion of the head. The other transducer is directed to the fetal trunk to observe trunk movements, isolated arm movements, breathing and hiccups. The observers both handle a keyboard to mark various types of fetal movements. In addition, two pedals are used to indicate visibility of the fetal orbit and the fetal trunk. Keyboards and pedals are connected to the computer's parallel interface. For the purpose of quality control and detailed differentiation of complex movement patterns, facilities for storage of ultrasound images on video tape are available.

The computer system consists of a PDP 11/34 processor together with an RA60 disk drive with a total capacity of 208 Mbytes for storage of programs and data files. Included are a multichannel AD-converter, a parallel interface, a terminal multiplexer with several terminals, a magtape drive for backup purposes. and a V80 plotter. The operating system is RSX-11M vs $4.2 \mathrm{D}$, offering multi-user timesharing. All programs are written in Fortran-IV vs 2.6.

\subsection{Storage of fetal heart rate and fetal move- ments}

The fetal heart rate is calculated from the RRinterval duration by applying the formula:

FHR $=60000 /$ RR-interval (FHR in beats/minute, RR-interval in $\mathrm{ms}$ )

A value for the fetal heart rate can be computed each time instant that a new RR-interval becomes available. Beat-to-beat variability is preserved only when consecutive RR-intervals are present, so it is preferable to store RR-intervals in the computer rather than a sampled analog fetal heart rate signal.
The way the system performs acquisition and storage of the firing frequency of the fetal heart is expressed in figure 1. The HP8030 generates a flash pulse each time a fetal R-peak is recognized in the total of electrical activity in the maternal abdomen. A home-made interface has a counter running at a clock frequency of $1250 \mathrm{~Hz}$. Each $200 \mathrm{~ms}$ the value of 250 is forwarded to the computer prior to counter reset, unless a flash pulse was received during this $200 \mathrm{~ms}$ period. In this case, the value of the counter at the precise moment of flash pulse arrival is sent to the computer. Values received by the computer are stored on disk in consecutive bytes. RR-intervals are calculated from this series of bytes using the following formula:

$$
\mathrm{RR} \text {-interval }=0.8 *((250-\mathrm{tx})+\mathrm{n} * 250+\mathrm{ty})
$$

In this formula, $\mathrm{tx}$ and ty are values of the counter in the range of $0 . .249$ indicating the moment a flash pulse was received during a $200 \mathrm{~ms}$ period, and $\mathrm{n}$ denotes the number of $200 \mathrm{~ms}$ periodes during which no flash pulse was detected. RRintervals are expressed in $\mathrm{ms}$. The factor 0.8 is the result of using a clock frequency of $1250 \mathrm{~Hz}$ instead of $1000 \mathrm{~Hz}$, giving a storage resolution of $0.8 \mathrm{~ms}$.

To indicate the occurrence and duration of various types of fetal movements, two keyboards are used with 4 and 8 keys respectively that can be operated simultaneously. The 12 keys of the keyboards and the two pedals are connected to 14 bits of the input register of the computer's parallel interface; the 2 remaining bits are not in use. The computer reads data from this register five times per second, resulting in a resolution of $200 \mathrm{~ms}$. A hold circuit is provided for in such a way that no keystroke will be lost. The register is reset automatically each time the data is read by the computer. For the accurate detection of movement types with a high repetition rate, such as breathing movements and regular mouthing movements, this resolution of $200 \mathrm{~ms}$ is insufficient [12]. Therefore two of the keys also supply a voltage level of 1 Volt to the $\mathrm{AD}$-converter. These signals are sampled 50 times per second, resulting in a resolution of $20 \mathrm{~ms}$. The data are stored on disk in separate files.

\subsection{Display}

Several display formats are available. The fetal heart rate can be plotted alone or in combination with fetal movement indicators. The plotter pro- 


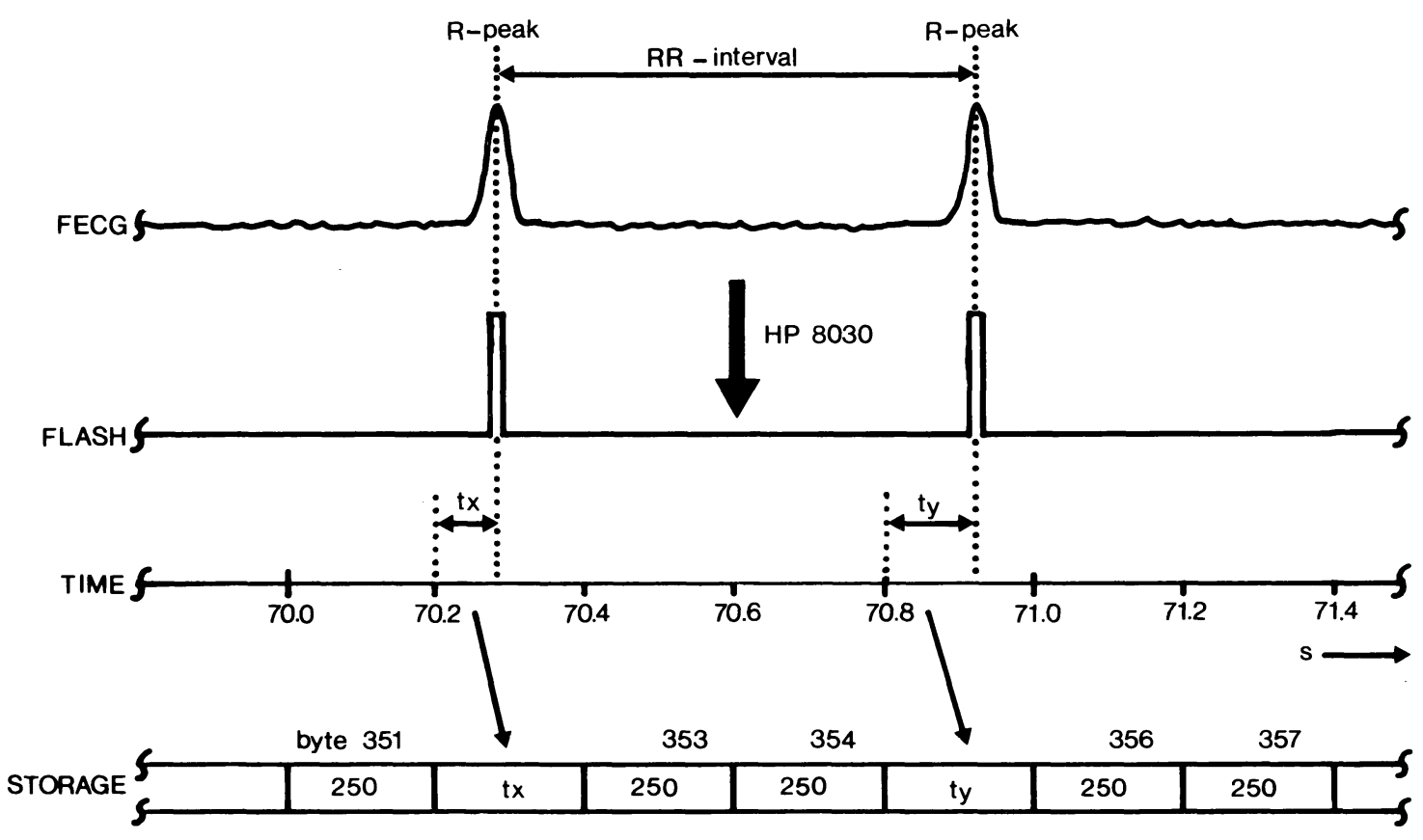

Figure 1. Storage of fetal heart rate.

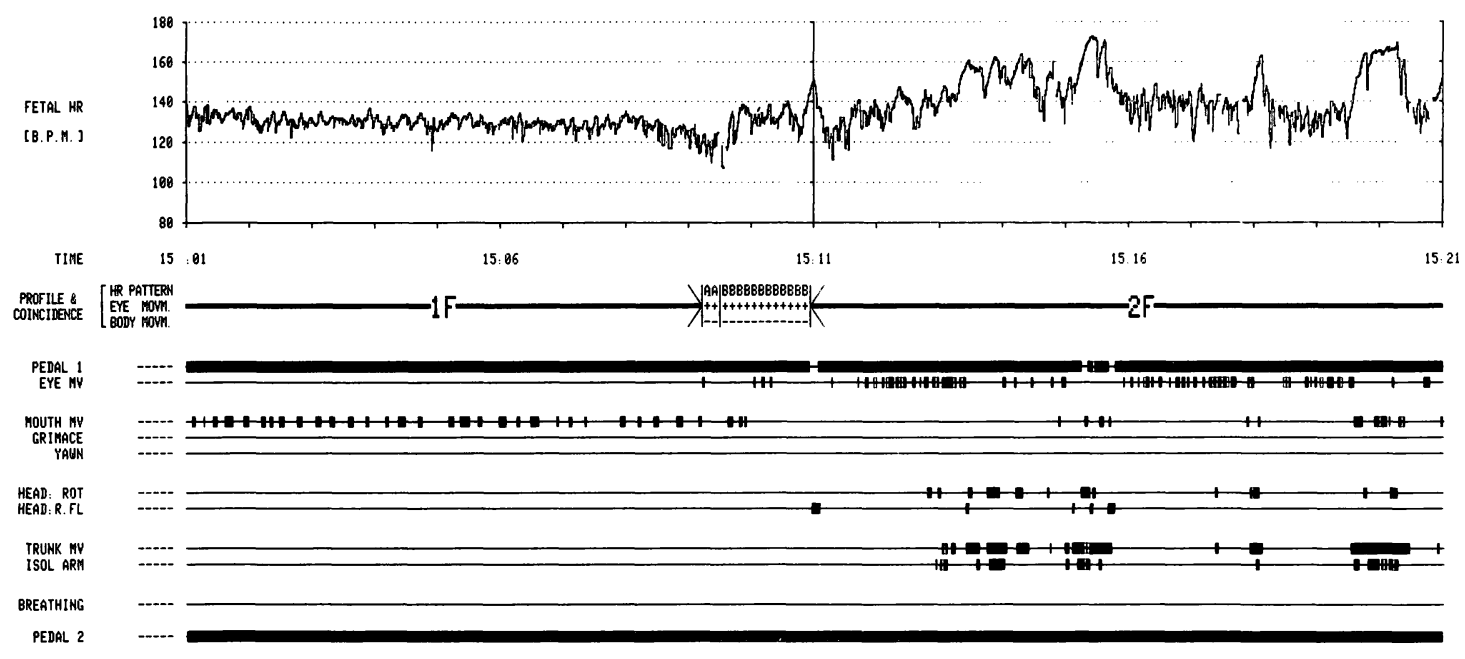

Figure 2. Part of a 2-hour recording at 38 weeks of gestation. The computer has identified a behavioral state 1F (15:01:00-15:09:10 hr), a behavioral state $2 \mathrm{~F}(15: 10: 58-15: 21: 00 \mathrm{hr})$, and a transitional period in between. The transitional period is described in terms of the state profile, i.e., the composing state parameters: heart rate pattern $\mathrm{A}$ or $\mathrm{B}$, eye movements present $(+)$, and body movements absent $(-)$.

grams allow compression for overviews and expansion for studying details of the stored signals. Furthermore, results of the process of state determination can be added to the original signals. Figure 2 shows an example.

\section{Processing and analysis}

\subsection{Artefact detection}

Detection of inappropriate RR-intervals in the fetal ECG, caused by missing R-peaks or induced 
noise, is performed applying the algorithm described by VAN GEIJN et al. [9]. In the first instance, those RR-intervals are accepted which meet the criteria:

$\mathrm{RR}_{\mathrm{i}}-0.43 * \mathrm{D}_{\mathrm{i}}<\mathrm{RR}_{\mathrm{i}+1}<\mathrm{RR}_{\mathrm{i}}+\mathrm{D}_{\mathrm{i}}$

with

$D_{i}=\operatorname{MAX}\left(20, R_{i}-300\right)$

$R R_{i}$ is the $i$-th $R R$-interval in a sequence, $R R_{i+1}$ is the next RR-interval. In this way, acceptance of an RR-interval depends on the value of the previous interval. For final acceptance of $R R_{+1}$, a minimum of three intervals that qualify to this formula must be present in succession.

The program that processes the RR-interval data file for detection of artefacts, creates a bitmap in which each bit corresponds to a byte in the data file. Rejected RR-intervals are marked by setting the bit in the bitmap corresponding to the byte referring to the bad R-peak. After completion, the program merges the bitmap in the data file. Programs that access the RR-interval data file also check the bitmap section of the file in order to exclude bad intervals from analysis.

\subsection{Determination of fetal behavioral states}

Fetal behavioral states are determined on the basis of particular fetal heart rate patterns and presence or absence of fetal eye and body movements. Body movements are, in this context, the collective of trunk movements, isolated arm movements, and rotation and retroflexion of the head.

\subsubsection{Fetal heart rate patterns: Delphi procedure}

For the time being, it is not possible to recognize fetal heart rate patterns in the tracings automatically. Presence or absence of fetal eye and body movements however, can be detected in the recordings by a computer program.

In order to classify the heart rate patterns, a Delphi group opinion procedure is applied consisting of 3 rounds [2]. During the first round three experts classify independently their own copies of all heart rate tracings, either the fetal ECG or the wide range Doppler ultrasound signal. Four fetal heart rate patterns are distinguished [6]:

pattern A: a stable heart rate pattern with a small oscillation bandwidth; pattern B: a heart rate pattern with a wider oscillation bandwidth than pattern $\mathrm{A}$, with frequent accelerations;

pattern C: a stable pattern with a wider oscillation band width than pattern A;

pattern $\mathrm{D}$ : an unstable pattern with large and longlasting accelerations, frequently fused into sustained tachycardia.

If the heart rate pattern does not meet any of the above mentioned criteria, the experts declare the segment involved as 'unidentifiable'. During the second round of the procedure the experts classify the same tracings again, but now they have access to the classifications of the other experts from round 1 , and are consequently able to adjust their opinion. During the third round, the classifications of the second round are evaluated. The start and stop times of those segments on which there is consensus between at least two of the three experts are entered into the computer.

\subsubsection{Fetal movements: extended automatic win- dow procedure}

Presence or absence of fetal eye and body movements is identified by a computer program implementing a moving window procedure. A window of 3 minutes duration is shifted continuously over the recorded patterns of fetal eye movements and fetal body movements separately. Eye movements and body movements are dealt with in the same way. The principle of the window technique is explained in figure 3. Figure $3 \mathrm{a}$ demonstrates the computerized version of the known window technique [6] as described earlier [1]. During phase 1 all segments where movements are absent for more than 3 minutes are identified and labeled. All remaining segments are temporarily regarded to be segments of presence of movements. During phase 2, all segments of presence of movements lasting shorter than 3 minutes are regarded to be shortlasting pertubations and are denoted as additional periods of absence of movements. Figure $3 \mathrm{~b}$ shows an extension of the window procedure, incorporating the influence of the pedal. Periods during which the pedal has been released indicate that the ultrasound image at the moment of recording was too bad to enable the observer to mark fetal movements correctly. In the extreme case, movements were continually present during pedal release. To simulate this condition, the computer artificially creates a new bar containing the original movement pattern, enhanced with the in- 
a

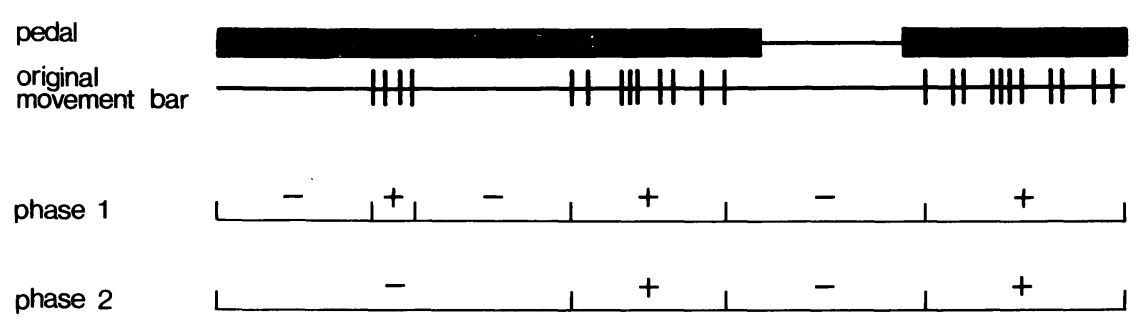

b artificial artificial
movement bar

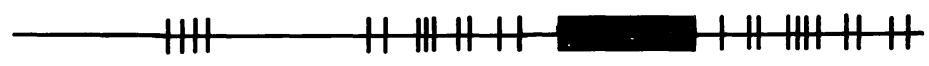

phase 3

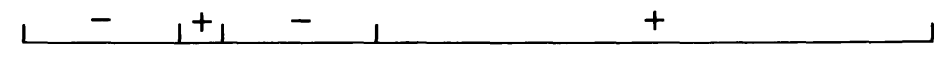

phase 4

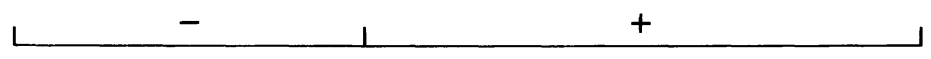

C

result

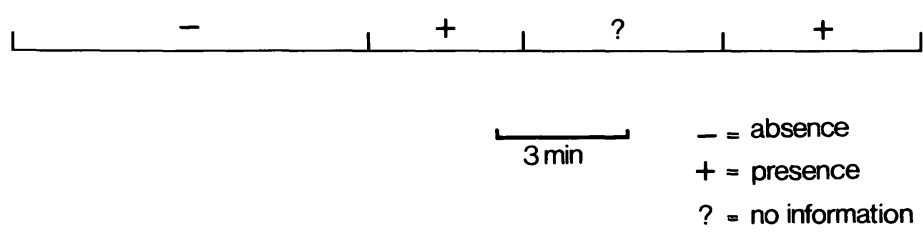

Figure 3. Extended automatic window procedure.

verse pedal pattern. Next, phase 3 and 4 are applied. These phases are essentially identical to phase 1 and 2, except that now the artificially created movement bar is used.

After phase 4 has been completed, the computer compares the results of this phase with the results of phase 2 . All differences between phase 2 and phase 4 are identified and labeled (figure 3c). Notice that the influence of the pedal release exceeds the duration of the release in the currently shown case. This procedure identifies periods of true absence, periods of true presence, and periods during which information of absence or presence is lacking. This whole procedure will be referred to as the extended automatic window procedure.

\subsubsection{Fetal behavioral states}

Determination of fetal behavioral states is performed by the computer combining the results of the Delphi procedure and the extended automatic window procedure, applying the following rules: state $1 \mathrm{~F}$ : heart rate pattern $\mathrm{A}$, eye movements absent, body movements absent; state $2 \mathrm{~F}$ : heart rate pattern $\mathrm{B}$, eye movements present, body movements present;

state $3 \mathrm{~F}$ : heart rate pattern $\mathrm{C}$, eye movements present, body movements absent;

state $4 \mathrm{~F}$ : heart rate pattern $\mathrm{D}$, eye movements present, body movements present.

Fetal behavioral states are indicated only if a segment fulfilling these rules lasts longer than three minutes. All segments in between two successive and different fetal behavioral states are called transitional periods.

\subsection{Fetal heart rate variability indices}

Long term and short term variability are assessed by computation of the Long Term Irregularity index [3], and the Interval Difference index [4, 9]. Both indices are defined over 30 -second periods of RR-intervals. 


\section{LTI $=$ interquartile range of}

$\sqrt{\frac{R_{i}^{2}+R R_{i}^{2}-1}{2}}$

ID $=$ interquartile range of

$\mathrm{G}_{\mathrm{i}} *\left(\mathrm{RR}_{\mathrm{i}}-\mathrm{RR}_{\mathrm{i}-1}\right)$

with

$\mathrm{G}_{\mathrm{i}}=\left(\frac{180}{\mathrm{MRR}_{\mathrm{i}}-320}\right)^{1.5}$

and

$\mathrm{MRR}_{\mathrm{i}}=\frac{\mathrm{RR}_{\mathrm{i}}+\mathrm{RR}_{\mathrm{i}}-1}{2}$

for

$$
\mathrm{MRR}_{\mathrm{i}}<381 \mathrm{~ms}: \mathrm{G}_{\mathrm{i}}=5 \quad(\mathrm{i}=2 \ldots \mathrm{n})
$$

Computed values are stored in a parameter file from which selections of data can be displayed or processed statistically. Selections can be based upon the behavioral state, or the presence or absence of a specific movement or group of movements.

\subsection{Analysis of fetal movements}

Calculation of duration and distribution of fetal movements can be performed for each movement type separately. Segments of a recording to be analysed are freely selectable. Results are presented numerically and in histograms. Movements sampled at 50 times per second, such as breathing movements, are analysed in a similar fashion. In addition, "rategrams" can be constructed by the computer. All output is provided with a statistical summary.

\footnotetext{
Abstract

Fetal heart rate and fetal movements provide information on the fetal condition. In the near term human fetus, four behavioural states have been described based upon heart rate patterns and presence or absence of eye and body movements. For our studies concerning fetal physiology as well as the influence of maternal antiepileptic medication and the effects of intrauterine growth retardation on the fetal condition, we developed a computerized system for acquisition and storage of fetal
}

\section{Discussion}

The employment of a computer in this particular research offers the possibility of accurate acquisition, storage, display and analysis of fetal heart rate and fetal movements. Furthermore one can process the data repeatedly with various settings of system parameters.

Concerning fetal movements, we are able to process 12 different types simultaneously. Of each single movement, the moment of occurrence as well as the duration are recorded. Our introduction of two pedals, which provides continuous information about the quality of the ultrasound images, is essential to obtain reliable data on fetal movements. Without this information statistical analysis of movement distribution and duration is inadequate.

As to fetal heart rate, variability indices and spectral analysis can be easily derived from the fetal ECG. Establishment of the baseline as well as identification of accelerations and decelerations are within reach. Our system synchronizes fetal movements and fetal heart rate in a way that their relationship can be analyzed in detail.

The determination of fetal behavioral states by hand is a time consuming technique, sensitive to mistakes. The automation of the window procedure which has been described in this paper has been a real asset in this respect. The introduction of the extended window procedure for the first time supplies a reliable method to discriminate between periods of true absence, periods of true presence and periods during which information of absence or presence is missing. This greatly attributes to the validity of the acquired data. However, human errors in the acquisition phase never can be excluded completely, and when the computer output is interpreted one has to bear in mind the biological origin of the data which may show substantial intra- and interindividual variation.

heart rate signals and observed fetal movements. Fetal heart rate is recorded using a commercially available monitor combined with a home-made computer interface. Fetal movements are observed using two real-time ultrasound units. The observers handle keyboards to mark occurrence and duration of various types of fetal movements, and pedals to mark the visibility of the observed part of the fetal body. Keyboards and pedals are scanned by the computer. Special techniques are used 
to store heart rate and movement signals in an efficient way. Three experts determine fetal heart rate patterns by application of a Delphi group opinion procedure. Fetal behavioral states are identified by the computer using the results of the Delphi procedure, and performing the so-called extended automatic window procedure.
This procedure identifies periods of presence and periods of absence of fetal eye and body movements, and incorporates the loss of visibility of the ultrasound images during the recording session. Fetal heart rate variability indices and distributions of fetal movements can be computed in the context of the fetal behavioral state concept.

Keywords: Computer techniques, fetal behavioral states, fetal heart rate, fetal mobility.

\section{Zusammenfassung}

Computergestiitzte Bewertung fetaler Verhaltenszustände Herzfrequenz und fetale Bewegungen liefern Informationen über den fetalen Zustand. Aufgrund von Herzfrequenzmustern und Auftreten von Augen- und Körperbewegungen können beim Feten am Ende der Schwangerschaft vier Verhaltenszustände unterschieden werden. Einerseits zur Untersuchung der fetalen Physiologie und andererseits um mögliche Einflüsse maternaler Antiepileptikamedikation und intrauteriner Mangelentwicklung auf das fetale Verhalten zu unterscheiden, entwickelten wir ein computergestütztes System zur Erfassung und Speicherung von Signalen der fetalen Herzfrequenz und der Körperbewegung. Bei der Registrierung der Herzfrequenz wird ein kommerziell verfügbarer Monitor verwendet, der über ein selbstgefertigtes Interface mit einem Computer verbunden ist. Fetale Bewegungen werden beobachtet und mit zwei Real-Time-Ultraschalleinheiten registriert. Die Untersucher verwenden Tastaturen, um das Auftreten und die Dauer der verschiedenen Bewe- gungsarten zu markieren, und Fußschalter, wenn die Bewegungen bestimmter Körperteile des Feten beobachtet werden. Tastaturen und Fußschalter werden vom Computer abgefragt. Besondere Techniken werden eingesetzt, um die Herzfrequenz und Signale der Bewegungen auf effiziente Weise abzuspeichern. Drei Experten bestimmen die fetalen Herzfrequenzmuster durch Anwendung einer ,Delphi group opinion'-Prozedur. Fetale Verhaltenszustände werden mit Hilfe des Computers unter Verwendung der Ergebnisse der Delphi-Prozedur durch Anwendung einer sog. erweiterten automatischen Fensterprozedur identifiziert. Dieses Verfahren erkennt die Phasen mit und ohne fetale Augen- und Körperbewegungen und berücksichtigt gleichzeitig die Phasen, in denen keine guten Ultraschallbilder während der Beobachtung zur Verfügung standen. Merkmale der fetalen Herzfrequenzvariabilität und die Verteilungen der fetalen Bewegungen können im Rahmen des Konzeptes der fetalen Verhaltenszustände errechnet werden.

Schlüsselwörter: Computertechniken, fetale Bewegungen, fetale Herzfrequenz, fetale Verhaltenszustände.

\section{Résumé}

\section{Détermination informatisée des états comportementaux} du fæetus

Le rythme cardiaque fœtal et les mouvements fœtaux nous donnent des renseignements sur l'état du fotus. Quatre sortes d'états comportementaux ont été décrits pour le foetus humain, basés sur des modèles de rythme cardiaque et sur la présence ou l'absence du mouvements oculaires ou corporels. Pour nos études sur la physiologie fœtale, l'influence de traitement médical antiépileptique de la mère et les effets du retard de croissance intrautérin sur l'état physique du foetus, nous avons développé un système informatique pour obtenir et conserver les signaux du rythme cardiaque fœtal et des mouvements fætaux observés. Le rythme cardiaque fotal est enregistré à l'aide d'un appareil de surveillance électrocardiographique en vente dans le commerce combiné avec un interface fait par nous-mêmes avec un ordinateur. Les mouvements fotaux sont observés à l'aide de deux unités ultrasonores en temps réel. Les observateurs se servent de claviers pour marquer la survenue et la durée des différents types de mouvements fotaux, et de pédales pour marquer la visibilité des parties observées du corps fœtal. L'ordinateur contrôle les claviers et les pédales. On a des techniques spéciales pour conserver le rythme cardiaque fotal et les signaux des mouvements du fœtus d'une manière efficace. Trois experts déterminent les modèles de rythme cardiaque en appliquant le procédé «Delphi group opinion". l'ordinateur identifie les états de comportement fœtal à l'aide des résultats du procédé Delphi et en exécutant un procédé dit de la fenêtre automatique. Ce dernier procédé identifie des périodes de présence et des périodes d'absence de mouvements oculaires et corporels et considère la disparition de la visibilité des images ultrasonores pendant la séance d'enregistrement. Les indices de variabilité du rythme cardiaque foetal et la distribution des mouvements fœtaux peuvent être calculés dans le contexte des états comportementaux du fetus.

Mots-clés: États comportementaux du fœtus, mobilité fœtale, rythme cardiaque fœtal, techniques informatiques.

Acknowledgements: Our studies are supported by grants from 'Het Praeventiefonds', The Netherlands. 


\section{References}

[1] Caron FJM, HP Van Geijn, EE Van Woerden, JM SWARTJES: Processing of fetal behavioural state patterns. In: KJ DALTON and RDS FAWDRY (eds): The Computer in Obstetrics and Gynaecology. IRL Press Limited, Oxford (1987) 179

[2] Dalkey N: An experimental study of group opinion: The Delphi method. Futures sept (1969) 408

[3] De HaAN J, JH Van Bemmel, B Versteeg, AFL VeTH, LAM Stolte, J JANSSENS, TKAB EsKes: Quantitative evaluation of fetal heart rate patterns. I. processing methods. Europ J Obstet Gynecol Reprod Biol 3 (1971) 95

[4] Jongsma HW, HP VAN Geijn, J DE HaAn: The analysis of heart rate variability in the perinatal period. In: W. KRAUSE (ed): Computerdiagnostik in der Geburtsmedizin. Friedrich Schiller Universität, Jena, (1978) 249

[5] MARTIN CB JR: Behavioral states in the human fetus. J Reprod Med 268 (1981) 425

[6] Nijhuis JG, HFR Prechtl, CB Martin JR., RSGM Bots: Are there behavioural states in the human fetus? Early Hum Dev 6 (1982) 177

[7] SwartJes JM, HP VAN GeIJN: Maternal perception of fetal movements: the optimal duration of a recording period. Europ J Obstet Gynecol Reprod Biol 25 (1987) 97

[8] Swartjes JM, HP Van Geijn, FJM Caron, EE VAN WOERDEN: Automated analysis of fetal behavioural states and state transitions. Excerpta Medica, International Congress Series, Elsevier 752 (1988) 39
[9] VAN Geijn HP, HW Jongsma, J DE HaAn, TKAB ESKES: Analysis of heart rate and beat-to-beat variability: Interval difference index. Am J Obstet Gynecol 138 (1980) 246

[10] VAn Geijn HP, HW Jongsma, J De HaAn, TKAB ESKES, HFR PRECHTL: Heart rate as an indicator of the fetal behavioural state: studies in the newborn and prospects for fetal heart rate monitoring. Am J Obstet Gynecol 136 (1980) 1061

[11] Van Geijn HP, JM Swartues, EE Van Woerden, FJM CARon, JTJ Brons, NFTh ARTs: Fetal behavioural states in epileptic pregnancies. Europ J Obstet Gynecol Reprod Biol 21 (1986) 306

[12] VAN WOERDEN EE, HP VAN GeIJN, FJM Caron, AW VAN DER VALK, JM SWARTJES, NFTh ARTS: Fetal mouth movements during behavioural state $1 \mathrm{~F}$ and 2F EUR J Obstet Gynecol Reprod Biol (1988) (in press)

[13] Van Woerden Ee, HP Van GeiJn, JM Swartjes, FJM Caron, JTJ Brons, NFTh ARTS: Fetal heart rhythms during behavioral state 1F EUR J Obstet Gynecol Reprod Biol 28 (1988) 29

F. J. M. Caron, M. Sc.

Department of Obstetrics and Gynecology

Academisch Ziekenhuis

Vrije Universiteit

De Boelelaan 1117

1007 MB Amsterdam, The Netherlands 